\title{
Save the ICU and save lives during the COVID-19 pandemic
}

\author{
Japan ECMOnet for COVID-19 ${ }^{1}$ and Nobuaki Shime ${ }^{2^{*}}$ (D)
}

\begin{abstract}
Appropriate critical care delivery for Coronavirus disease 2019 (COVID-19) is a cornerstone in saving lives. Earlier publications worldwide demonstrate higher mortality among patients receiving mechanical ventilation in intensive care units during "surges" in the number of cases. In contrast, lower mortality outcomes are evident in Japan using CRISIS [CRoss Icu Searchable Information System] data by the national registry, Japan ECMOnet for COVID-19. This highlights the need for scientific analysis of the medical factors contributing to high survival rates and social factors associated with low case "surges," to gain insight into protective strategies for possible coming waves in the COVID-19 pandemic.
\end{abstract}

The Coronavirus disease 2019 (COVID-19) pandemic is a novel challenge for critical care systems worldwide. Appropriate critical care delivery for acute respiratory failure is a cornerstone in saving the lives of patients. A recent publication of JAMA [1] reports a large-scale observational study describing the clinical characteristics and outcomes of patients with COVID-19 in the New York City area. Among patients who were discharged or who died $(n=2634), 373(14 \%)$ were treated in the intensive care unit (ICU), and 320 (12\%) received invasive mechanical ventilation. Surprisingly, $88 \%$ of patients died while receiving mechanical ventilation. Similarly, results from a national registry in the UK [2] indicate that $62 \%$ of patients with confirmed COVID-19 and requiring advanced respiratory support in the ICU (2175/3508) died. Moreover, a report from the Lombardy region of Italy reported that among 1591 patients infected with SARSCoV-2 admitted to ICUs, $26 \%$ died, $16 \%$ were discharged, and $58 \%$ were still in the ICU [3]. These high mortality rates could be partly explained by overwhelmed ICU

\footnotetext{
Correspondence: shime@koto.kpu-m.ac.jp
}

${ }^{2}$ Department of Emergency and Critical Care Medicine, Graduate School of Biomedical \& Health Sciences, Hiroshima University, 1-2-3 Kasumi, Minami-ku, Hiroshima 734-8551, Japan

Full list of author information is available at the end of the article services owing to exponential surges in the number of cases of COVID-19.

Japan experienced its first wave of patients with COVID-19 beginning in late March, which reached its peak in late April. However, the total number of patients at the peak in Japan was relatively small. On April 27, a maximum of 10,211 patients were treated in a single day nationwide, and a total of 407 patients (4\%) nationwide were receiving or had received mechanical ventilation (captured using CRISIS [CRoss Icu Searchable Information System] by the national registry, Japan ECMOnet for COVID-19 [4, 5]) (Fig. 1). These totals accounted for about one-third of the critical care beds available specifically for COVID-19 care. Interestingly, 288 patients $(60 \%)$ were weaned from the ventilator and survived, 79 died, and 114 were still receiving mechanical ventilation on May 16, 2020 (3 weeks after the peak, Fig. 1); the expected mortality rates were between 16 and 48\%, calculated by assuming all patients remaining on a ventilator will survive or die. Moreover, veno-venous extracorporeal membrane oxygenation (ECMO) was performed in 159 patients up to May 16. Of these, 92 patients were weaned from ECMO, 33 died, and 34 continued to receive ECMO, with expected mortality between 20 and $42 \%$. 


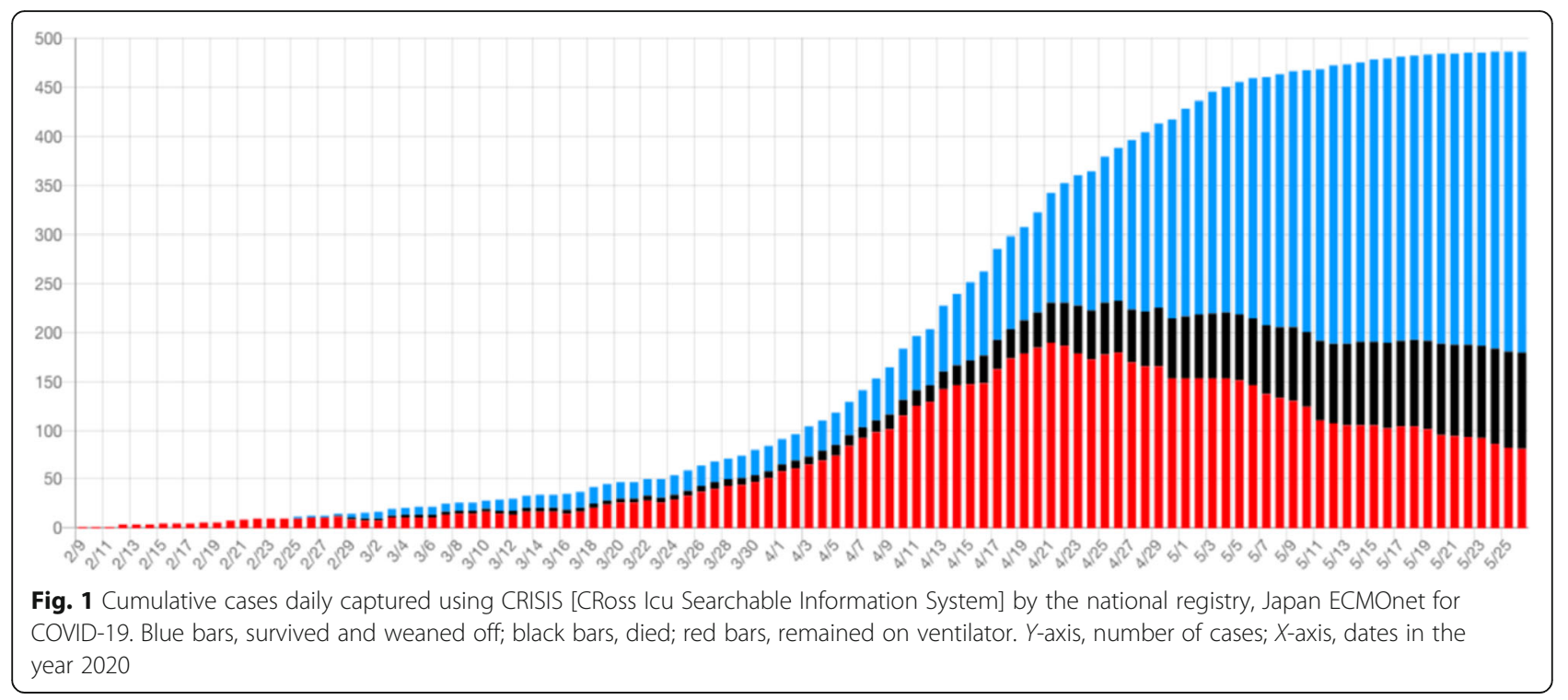

Although all the aforementioned studies are preliminary reports, that is, a considerable number of patients were still in the ICU on a ventilator, a relatively low mortality outcome is expected in the Japanese results. This suggests that reducing a "surge" in cases, which can overwhelm the capacity of the ICU, is critical for maintaining ordinary ICU functions, avoiding life-and-death triage decisions, and ultimately, saving the lives of patients in the face of this novel threat. More detailed scientific analysis and careful explanation of the data will be needed, considering the indications; patient background including age, comorbidities, or acute illness severity; and details of ventilator management, all factors that can considerably affect survival outcomes. In addition, analyses of the social factors contributing to flattening of the peak itself are urgently required as such findings could offer important insight into nationwide protective strategies against possible "next waves" of the COVID-19 pandemic in countries worldwide.

\section{Abbreviations}

COVID-19: Coronavirus disease 2019; CRISIS: CRoss Icu Searchable Information System; ECMO: Extracorporeal membrane oxygenation; ICU: Intensive care unit; SARS-CoV-2: Severe acute respiratory syndrome coronavirus 2

\section{Acknowledgements}

We thank Analisa Avila, ELS, of Edanz Group (https://en-author-services. edanzgroup.com/) for editing a draft of this manuscript. We acknowledge the below members. The members of Japan ECMOnet for COVID-19 contributed equally to this letter: Ryuzo Abe, MD, PhD; Naofumi Bunya, MD, PhD; Tomoyuki Endo, MD, PhD; Yuji Fujino, MD, PhD, Japanese Society of Respiratory Care Medicine (chair); Kensuke Fujita, MD; Kenji Fujizuka, MD; Yoshihiro Hagiwara, MD; Jun Hamaguchi, MD, MPH; Yoshitaka Hara, MD, PhD; Eiji Hashiba, MD, PhD; Satoru Hashimoto, MD, PhD, Japan web-based real-time nationwide registry for COVID-19, CRISIS (chair); Noriyuki Hattori, MD, PhD; Kota Hoshino, MD; Shinichi ljuin, MD; Takanari Ikeyama, MD; Shingo Ichiba, MD, PhD; Wataru Iwanaga, MD; Yoshiaki Iwashita, MD, PhD; Masafumi Kanamoto, MD, PhD; Hitoshi Kaneko, MD; Kaneyuki Kawamae, MD, PhD; Toru Kotani, MD; Yasuaki Koyama, MD; Keibun Liu, MD, PhD; Tomohiko Masuno, MD, PhD; Naoto Morimura, MD, PhD; Tomoyuki Nakamura, MD; Masaki
Nakane, MD, PhD; Michitaka Nasu, MD; Osamu Nishida, MD, PhD, Japanese Society of Intensive Care Medicine (chair); Masaji Nishimura, MD, PhD, Japanese Society of Intensive Care Medicine (former chair); Kanae Ochiai, MD; Takayuki Ogura, MD, PhD; Shinichiro Ohshimo, MD, PhD; Keisuke Oyama, MD; Junichi Sasaki, MD, PhD; Ryutaro Seo, MD; Takeshi Shimazu, MD, PhD, Japanese Association for Acute Medicine (chair); Nobuaki Shime, MD, PhD; Keiki Shimizu, MD; Hiroyuki Suzuki, MD; Shuhei Takauji, MD, PhD; Shinhiro Takeda, MD, PhD, Japan ECMOnet for COVID-19 (chair); Ichiro Takeuchi, MD, PhD; Mumon Takita, MD; and Hayato Taniguchi, MD, PhD.

\section{Author's contributions}

N. Shime, S. Hashimoto, and S. Takeda drafted the manuscript; all other members equally supervised the manuscript. The authors read and approved the final manuscript.

\section{Funding}

Funded by Health and Labor Sciences Research Grants, Ministry of Health, Labor, and Welfare, Japan (\#19HA1003).

\section{Availability of data and materials}

The datasets used and analyzed during the current study are available from the corresponding author on reasonable request.

Ethics approval and consent to participate Not applicable.

Consent for publication

Not applicable.

\section{Competing interests}

The authors declare that they have no competing interests.

\section{Author details}

${ }^{1}$ Kawaguchi Heart and Lung Hospital, 1-1-51 Maekawa-cho, Kawaguchi, Saitama Prefecture 333-0842, Japan. ${ }^{2}$ Department of Emergency and Critical Care Medicine, Graduate School of Biomedical \& Health Sciences, Hiroshima University, 1-2-3 Kasumi, Minami-ku, Hiroshima 734-8551, Japan.

Received: 29 May 2020 Accepted: 3 June 2020

Published online: 15 June 2020

\section{References}

1. Richardson S, Hirsch JS, Narasimhan M, Crawford JM, McGinn T, Davidson $\mathrm{KW}$, et al. Presenting characteristics, comorbidities, and outcomes among 5700 patients hospitalized with COVID-19 in the New York City area. JAMA-J Am Med Assoc. 2020;10022:1-8. https://doi.org/10.1001/jama.2020.6775. 
2. ISARIC. International Severe Acute Respiratory and Emerging Infection Consortium: COVID-19 report 2 April 2020. 2020; https://isaric.tghn.org/ about/.

3. Grasselli G, Zangrillo A, Zanella A, Antonelli M, Cabrini L, Castelli A, et al. Baseline characteristics and outcomes of 1591 patients infected with SARS CoV-2 admitted to ICUs of the Lombardy region, Italy. JAMA - J Am Med Assoc. 2020. https://doi.org/10.1001/jama.2020.5394.

4. Japan ECMOnet for COVID-19: Telephone consultations for cases with severe respiratory failure caused by COVID-19. J Intensive Care. 2020;8:24. doi: https://doi.org/10.1186/s40560-020-00440-9.

5. Japan ECMOnet for COVID-19. Nationwide system to centralize decisions around ECMO use for severe COVID-19 pneumonia in Japan (Special Correspondence). J Intensive Care. 2020;8:29. https://doi.org/10.1186/s40560020-00445-4.

\section{Publisher's Note}

Springer Nature remains neutral with regard to jurisdictional claims in published maps and institutional affiliations.

Ready to submit your research? Choose BMC and benefit from:

- fast, convenient online submission

- thorough peer review by experienced researchers in your field

- rapid publication on acceptance

- support for research data, including large and complex data types

- gold Open Access which fosters wider collaboration and increased citations

- maximum visibility for your research: over $100 \mathrm{M}$ website views per year

At $\mathrm{BMC}$, research is always in progress.

Learn more biomedcentral.com/submissions 